\title{
Typical clinical and neuroimaging features in Sjögren-Larsson syndrome
}

\section{Características clínicas e neurorradiológicas típicas na síndrome de Sjögren-Larsson}

Anderson Rodrigues Brandão de Paiva', Uirá Souto Melo², Fernando Freua ${ }^{1}$, Denise Dória', Katiane Sayão

Souza Cabral', Lúcia Inês Macedo-Souza², Leandro Tavares Lucato³, Fernando Kok'

Sjögren-Larsson syndrome is an autosomal recessive disorder characterized by ichthyosis, intellectual disability, spastic paraplegia, macular dystrophy, and leukoencephalopathy. It is caused by mutations in $A L D H 3 A 2$, which leads to accumulation of long chain fatty alcohols. Herein we report on a 28-year-old man with congenital ichthyosis (Figure A) and profound intellectual disability, who is severely spastic and had undergone several orthopedic procedures for correction of deformities. Brain MRI disclosed leukoencephalopathy and cortical atrophy (Figure B), while MR spectroscopy allowed identification of peaks assigned to lipids (Figure C). Sequencing of $A L D H 3 A 2$ revealed he is a compound heterozygote for two previously reported splice site mutations: maternally inherited c.798+5G>A, and paternally transmitted c.1108-1G>C. Treatment of Sjögren-Larsson syndrome is symptomatic. ${ }^{1,23}$
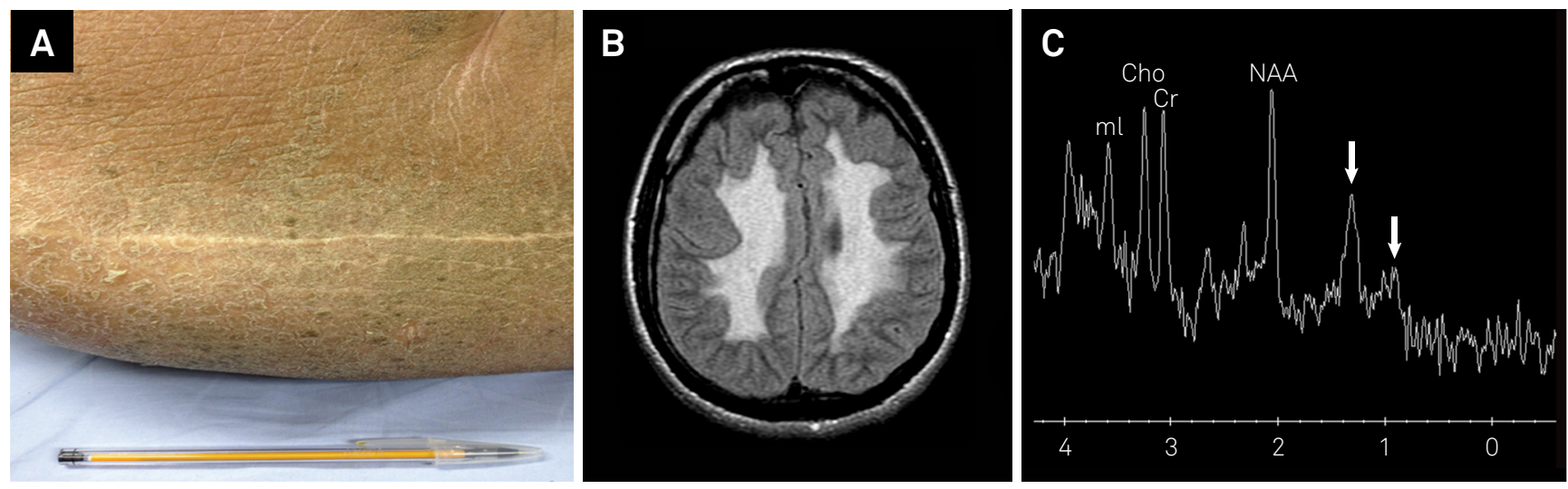

Figure. A. Congenital ichthyosis. B. MRI: axial FLAIR image demonstrates diffuse leukoencephalopathy. C. MR spectroscopy, single voxel, echo time $=30 \mathrm{~ms}$, region of interest placed in the parieto-occipital white matter, discloses peaks assigned to lipids in 0.8-0.9 ppm and in 1.3 ppm (arrows), which can be appreciated in the disease. The NAA peak is decreased (signaling neuroaxonal loss or dysfunction) and the $\mathrm{ml}$ peak is increased (probably related to gliosis). NAA: N-acetyl aspartate; Cr: creatine; Cho: choline; ml: myo-inositol.

\section{References}

1. Lossos A, Khoury M, Rizzo WB, Gomori JM, Banin E, Zlotogorski A. et al. Phenotypic variability among adult siblings with SjogrenLarsson syndrome. Arch Neurol. 2006;63(2):278-80. https://doi.org/10.1001/archneur.63.2.278

2. Willemsen MAAP, Graaf M, Knaap MS, Heerschap A, Domburg PHMF, Gabreels FJM et al. MR imaging and proton MR spectroscopic studies in Sjogren-Larsson syndrome: characterization of the leukoencephalopathy. AJNR Am. J. Neuroradiol. 2004;25(4):649-57.

3. Rizzo W, Carney G, Lin Z. The molecular basis of SjögrenLarsson syndrome: mutation analysis of the fatty aldehyde dehydrogenase gene. Am J Hum Genet. 1999;65(6):1547-60. https://doi.org/10.1086/302681

\footnotetext{
'Universidade de São Paulo, Hospital das Clínicas, Departamento de Neurologia, São Paulo SP, Brasil;

¿Universidade de São Paulo, Centro de Estudos do Genoma Humano, São Paulo SP, Brasil;

${ }^{3}$ Universidade de São Paulo, Hospital das Clínicas, Instituto de Radiologia, São Paulo SP, Brasil.

Correspondence: Anderson Rodrigues Brandão de Paiva; Rua Waldemar Falcão, 1547 / ap 1602A; 40295-010 Salvador BA, Brasil; E-mail: arbrandao@oi.com.br Conflict of interest: There is no conflict of interest to declare.

Received 03 January 2018; Received in final form 26 January 2018; Accepted 28 January 2018.
} 